\title{
Cellular localization of guanylin and uroguanylin mRNAs in human and rat duodenal and colonic mucosa
}

\author{
Øystein Brenna $^{1,2}$ - Marianne W. Furnes ${ }^{2}$ Bjørn Munkvold ${ }^{2}$ - Mark Kidd ${ }^{2}$. \\ Arne K. Sandvik 1,2,3 • Björn I. Gustafsson ${ }^{1,2}$
}

Received: 7 February 2016/Accepted: 3 March 2016/Published online: 5 April 2016

(C) The Author(s) 2016. This article is published with open access at Springerlink.com

\begin{abstract}
Guanylin (GUCA2A/Guca2a/GN) and uroguanylin (GUCA2B/Guca2b/UGN) are expressed in the gastrointestinal tract and have been implicated in ion and fluid homeostasis, satiety, abdominal pain, growth and intestinal barrier integrity. Their cellular sources are debated and include goblet cells, entero-/colonocytes, enteroendocrine (EE) cells and tuft cells. We therefore investigated the cellular sources of GN and UGN mRNAs in human and rat duodenal and colonic epithelium with in situ hybridization (ISH) to determine coexpression with Chromogranin A ( $C H G A / C h g a / C g A$; enterochromaffin $[\mathrm{EC}]$ cells), defensin alpha 6 (DEFA6/Defa6; Paneth cells), mucin 2 (MUC2/Muc2; goblet cells) and selected tuft cell markers. GUCA2A/Guca2a expression was localized to goblet cells and colonocytes in human and rat colon. In human duodenum, GUCA2A was expressed in Paneth cells and was scarce in villous epithelial cells. In rat duodenum, Guca2a was only localized to goblet cells. Guca $2 b$ was focally expressed in rat colon. In human and rat duodenum and in human colon, GUCA2B/Guca2b was expressed in dispersed solitary epithelial cells, some with a
\end{abstract}

Electronic supplementary material The online version of this article (doi:10.1007/s00441-016-2393-y) contains supplementary material, which is available to authorized users.

Øystein Brenna

oystein.brenna@stolav.no; oystein.brenna@ntnu.no

1 Department of Gastroenterology and Hepatology, St. Olavs Hospital, Trondheim University Hospital, Trondheim, Norway

2 Department of Cancer Research and Molecular Medicine, Norwegian University of Science and Technology,

Trondheim, Norway

3 Centre of Molecular Inflammation Research, Norwegian University of Science and Technology, Trondheim, Norway tuft cell-like appearance. Neither GUCA2A nor GUCA2B were co-expressed with $C H G A$ in human duodenal cells. Consequently, EC cells are probably not the major source of human GN or UGN but other EE cells as a source of GN or UGN are not entirely excluded. No convincing overlap with tuft cell markers was found. For the first time, we demonstrate the cellular expression of GUCA2B in human duodenum. The specific cellular distribution of both GN and UGN differs between duodenum and colon and between human and rat intestines.

Keywords Chromogranin A · Enteroendocrine cells . Guanylin · Tuft cells · Uroguanylin

\section{Introduction}

Guanylin (GN [gene name: GUCA2A]) and Uroguanylin (UGN $[G U C A 2 B]$ ) are endogenous ligands for the guanylate cyclase-C (GC-C [GUCY2C]) receptor. Heat-stable enterotoxin (ST) derived from Escherichia coli was first reported to elicit chloride and water secretion through guanylate cyclase and cyclic guanosine-3',5'-monophosphate (cGMP) activation (Field et al. 1978; Hughes et al. 1978). The specific GC-C receptor for ST was cloned in 1990 (Schulz et al. 1990). GUCY2C (GC-C) is expressed throughout the intestinal epithelium from duodenum to colon in human, rat and other mammals (Krause et al. 1994; Qian et al. 2000). The endogenous ligands for GC-C were discovered in 1992 and 1993 (Currie et al. 1992; Hamra et al. 1993). Both GUCA2A/ Guca $2 a(\mathrm{GN})$ and GUCA2B/Guca2b (UGN) are highly expressed in epithelial cells of the gastrointestinal (GI) tract (Beltowski 2001) and are secreted into the GI lumen but are also found in the systemic circulation (Date et al. 1996; Hess et al. 1995). GN and UGN are complementary in the GI tract, 
as GN increases in the cranio-caudal direction and vice-versa for UGN, possibly reflecting the $\mathrm{pH}$ optima for GN and UGN and also the resistance of UGN to chymotrypsin (Sindic and Schlatter 2006; Whitaker et al. 1997). Binding to GC-C in the intestinal epithelium leads to an intracellular increase of cGMP with subsequent activation of the cystic fibrosis transmembrane conductance regulator (CFTR), secretion of chloride and bicarbonate and inhibition of the sodium-hydrogen exchanger (NHE3), with resulting net water secretion (Field 2003). GC-C signaling has also been implicated in the regulation of satiety (Valentino et al. 2011), irritable bowel syndrome (IBS) and abdominal pain (Castro et al. 2013; Chey et al. 2012), tumor growth (Lin et al. 2010; Wilson et al. 2014) and the maintenance of intestinal barrier function (Han et al. 2011). Furthermore, a gain of function mutation has recently been discovered in a Norwegian family with chronic diarrhea and susceptibility to terminal ileitis (Fiskerstrand et al. 2012). GC-C agonists are now used in the treatment of constipationdominated IBS.

Recently, we reported that $G U C A 2 A, G U C A 2 B$ and $G U C Y 2 C$, plus several steps of the GC-C signaling pathway, are down-regulated in inflammatory bowel disease (IBD). This may sustain a disrupted epithelial barrier, influence growth and epithelial renewal and possibly have implications in IBD pathogenesis (Brenna et al. 2015).

Since their discovery, the cellular sources of both GN and UGN have been investigated and debated. Both peptides have been linked to enteroendocrine (EE) cells in the GI tract. GN has been found not only in serotonin-producing enterochromaffin (EC) cells (Cetin et al. 1994; Hill et al. 1995) and in somatostatin-producing (D) cells (Ieda et al. 1998) but also in goblet cells and/or colonocytes (Cohen et al. 1995, 1998; Date et al. 1996; Lewis et al. 1993; Li and Goy 1993; Li et al. 1995) and in Paneth cells of the small intestine (Cohen et al. 1998; Date et al. 1996; de Sauvage et al. 1992). UGN has likewise been linked to EE/EC cells (Cui et al. 2000; Hess et al. 1995; Perkins et al. 1997), EC-like (ECL) cells (Date et al. 1999; Nakazato et al. 1998) and tuft cells (Kokrashvili et al. 2009).

As considerable divergence is present in previous findings, we aimed to investigate the cellular expression/localization of endogenous GUCA2A/Guca2a (GN) and GUCA2B/Guca2b (UGN) by means of a highly sensitive and specific in situ hybridization (ISH) method (Sordal et al. 2013) in human and rat duodenum and colon.

\section{Materials and methods}

\section{Tissue}

Human duodenal endoscopic pinch biopsies from healthy individuals and colonic endoscopic pinch biopsies from healthy controls included in a large IBD study, as approved by the
Regional Medical Research Ethics Committee (approval no. 5.2007.910) and registered in the Clinical Trials Protocol Registration System (identifier NCT00516776), were collected. Whole duodenal and colonic sections from female Sprague Dawley rats (Taconic Farms, Hallingore, Denmark) weighing 200 - $250 \mathrm{~g}$ were extirpated under general anesthesia of the animals, which were thereafter killed by exsanguination. The general care and use of the animals were in accordance with the European Convention for the Protection of Vertebrate Animals used for Experimental and other Scientific purposes.

\section{In situ hybridization}

Human and rat biopsies were fixed in $4 \%$ formaldehyde for 3-5 days before being embedded in paraffin. Sections $(4 \mu \mathrm{m}$ thick) were mounted on slides and warmed for $1 \mathrm{~h}$ at $60{ }^{\circ} \mathrm{C}$ to ensure proper adhesion. Slides were deparaffinized in NeoClear, dehydrated in $100 \%$ ethanol and air-dried.

ISH was performed by using the RNAscope 2.0 and 2-plex chromogenic assay kits (Advanced Cell Diagnostics, Hayward, Calif., USA) following the protocol provided by the manufacturer. All human and rat probes for ISH were designed and purchased from Advanced Cell Diagnostics. The probes used are shown in Table 1 with gene and corresponding peptide/protein names.

Serial sections were used for single-plex ISH. Adjoining sides of the sections were mounted facing up on the slides. After dehydration and air-drying treatment, the following steps were conducted: peroxidase blocker (Pretreat 1), gentle boiling (Pretreat 2) for $15 \mathrm{~min}$ and protease (Pretreat 3) for $30 \mathrm{~min}$ at $40{ }^{\circ} \mathrm{C}$. After the pretreatment steps, the target probe was applied and hybridized for $2 \mathrm{~h}$ at $40^{\circ} \mathrm{C}$. Subsequently, the amplification steps $(A m p 1-6)$ including application of a horseradish peroxidase (HRP)-linked labeling probe were performed prior to DAB (diaminobenzidine) visualization (10 min; DAB was provided by the manufacturer) and counterstaining with hematoxylin for $2 \mathrm{~min}$. For duplex ISH, the slides were dehydrated in $100 \%$ ethanol after Pretreat 2 and air-dried again. Thereafter, Pretreat 3 was applied for $30 \mathrm{~min}$ at $40^{\circ} \mathrm{C}$. The target probe was subsequently applied for $2 \mathrm{~h}$ at $40^{\circ} \mathrm{C}$. As in single-plex ISH, signal amplification was performed in the next step. The 2-plex signal amplification system differs slightly from single-plex ISH. Amplification step 4 consists of a mixture of $A m p 4 A$ and $4 B$ designed specifically for Channel $\mathrm{C} 1$ and Channel $\mathrm{C} 2$ target probes, which results in a different color reaction after application of the chromogens. Channel C1 uses HRP-linked (green/blue) and Channel C2 uses alkaline phosphatase (AP)linked (red) labeling probes. The duplex ISH slides were counterstained in hematoxylin for $30 \mathrm{~s}$, immersed in $0.02 \%$ aqueous ammonia solution and air-dried at $60^{\circ} \mathrm{C}$ for $15 \mathrm{~min}$, before the mounting step. 
Table 1 Overview of in situ hybridization (ISH) probes used (gene names of ISH probes together with their respective peptide/protein name and accession numbers)

\begin{tabular}{lll}
\hline Gene name & Peptide/protein & Accession number \\
\hline Human probes & & \\
GUCA2A & Guanylin (GN) & NM_033553 \\
GUCA2B & Uroguanylin (UGN) & NM_007102.2 \\
CHGA & Chromogranin A (CgA) & NM_001275.3 \\
DEFA6 & Defensin, alpha 6 & NM_001926.3 \\
MUC2 & Mucin 2 & NM_002457.2 \\
DCLK1 & Doublecortin-like kinase 1 & NM_001195415.1 \\
GNAT3 & $\alpha$-Gustducin & NM_001102386.1 \\
SOX9 & Sex-determining region Y-box 9 & NM_000346.3 \\
TRPM5 & Transient receptor potential cation channel & NM_014555.3 \\
INSM1 & Insulinoma-associated 1 & NM_002196.2 \\
Rat probes & & \\
Guca2a & & NM_013118.1 \\
Guca2b & Guanylin (GN) & NM_022284.2 \\
Chga & Uroguanylin (UGN) & NM_021655.2 \\
Defa6 & Chromogranin A (CgA) & NM_001033076.1 \\
Muc2 & Defensin, alpha 6 & XM_003749023.1 \\
Dclk1 & Mucin 2 & NM_053343.3 \\
Gnat3 & Doublecortin-like kinase 1 & NM_173139.1 \\
Sox9 & $\alpha$-Gustducin & XM_003750950.1 \\
Trpm5 & Sex-determining region Y-box 9 & NM_001191896.1 \\
Insm1 & Transient receptor potential cation channel & XM_006224680.1 \\
\hline & Insulinoma-associated 1 &
\end{tabular}

\section{Immunohistochemistry}

We performed immunohistochemistry (IHC) for GN (human) and Dclk1 (human and rat). Because of the lack of appropriate antibodies, we were not able to carry out IHC for GN (rat) or UGN (human and rat). Serial sections with adjoining sides facing up on the slides were used to determine the possible co-localization of GUCA2B/Guca2b (ISH) and Dclk1 (IHC).

GN IHC on human duodenal and colonic biopsies was performed with anti-GN (HPA018215; Atlas Antibodies, Stockholm, Sweden; dilution 1:50 or 1:100), as previously described (Brenna et al. 2015). Dclk1 IHC (ab31704; Abcam, Cambridge, UK; dilution 1:100) was similarly carried out, apart from antigen retrieval in citrate buffer, $\mathrm{pH} 6$. Antibody detection was performed with secondary antibody (Dako REAL EnVision/HRP, Rabbit Mouse; Dako Denmark, Glostrup, Denmark). DAB (Dako REAL Substrate Buffer and Dako REAL DAB + Chromogen; Dako Denmark) was used as chromogen. Hematoxylin was used for counterstaining.

\section{Cell counting}

Whole sections from human duodenum were examined and the total number of GN (IHC)- or GUCA2A (ISH)-positive cells was separately counted in crypt and villous epithelium. For human and rat duodenum, the number of $G U C A 2 B$ /
Guca $2 b$ and CHGA/Chga expressing cells was counted in 4-8 non-overlapping visual fields $(200 \times)$ of two representative sections.

\section{Image capture and processing}

Images were captured by using a Nikon Eclipse E400 microscope (Nikon Instruments Europe, Amsterdam, Netherlands) and Nikon NIS-Elements BR 3.00 Imaging Software (Nikon Instruments Europe BV). Automatic white balance was used and the images were stored as TIFF-files. Figures were created in Adobe Photoshop CS5 (Adobe Systems, San Jose, Calif., USA).

\section{Results}

In rat duodenum, Guca2a (GN) was localized to Muc2-expressing goblet cells but was not expressed in Defa6-positive Paneth cells (Fig. 1a, b; see also Fig. S1a-f). In human duodenum, however, GUCA2A was expressed in DEFA6-positive Paneth cells and in addition, in a few scattered epithelial cells of the duodenal villi (Fig. 1c, d). In both rat and human colonic mucosa, Guca2a/GUCA2A was expressed in the entire surface epithelium, thus being present in both goblet cells and colonocytes (Fig. 1e, f). 

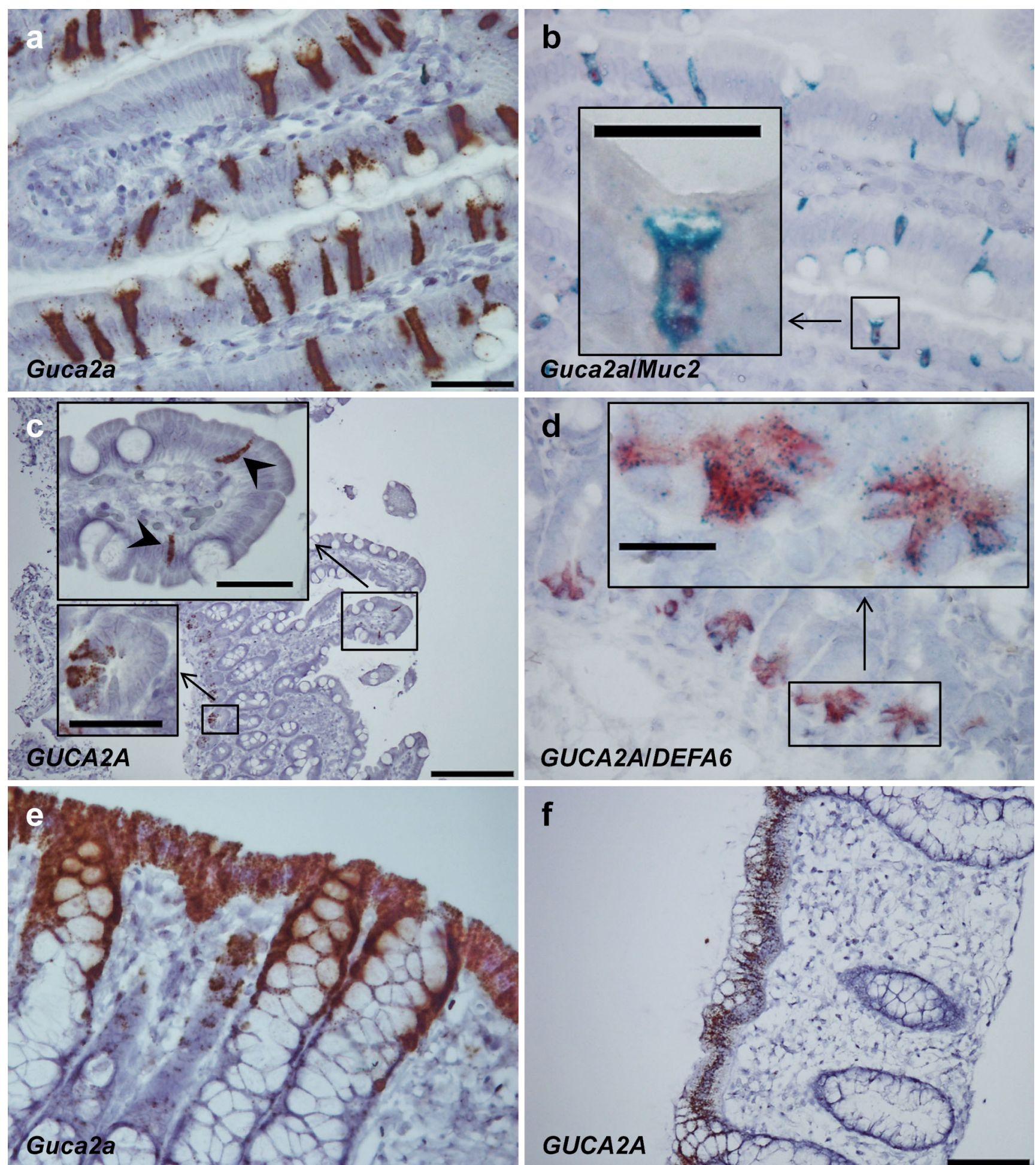

Fig. 1 Guca2a and GUCA2A expression (guanylin) in rat and human duodenum and colon. a Guca $2 a$-expressing cells in rat duodenal mucosa have goblet cell morphology. b Duplex in situ hybridization (ISH) showing that Guca2a (red) and Muc2 (blue) in rat duodenal mucosa are coexpressed in goblet cells. c GUCA2A-expressing cells in human duodenum are localized basally in crypts (small insert) and in scattered cells with a slender shape present in the duodenal villi (large insert, arrowheads). d Duplex ISH for GUCA2A (blue) and DEFA6 (red)

demonstrates co-expression in human duodenal crypts indicating GUCA2A expression in Paneth cells (large insert). e In the rat colon Guca2a is abundantly expressed in virtually all surface epithelial cells but is not expressed from the middle to the basal parts of the crypt epithelium. $\mathbf{f} G U C A 2 A$ expression in the human colon is also localized to virtually all cells of the surface epithelium but is not expressed in the middle or basal parts of the crypt epithelium. Bars $20 \mu \mathrm{m}$ (inserts in $\mathbf{b}$, d), $50 \mu \mathrm{m}(\mathbf{a}, \mathbf{b}, \mathbf{d}, \mathbf{e}$, inserts in c), $100 \mu \mathrm{m}(\mathbf{f}), 200 \mu \mathrm{m}$ (c) 

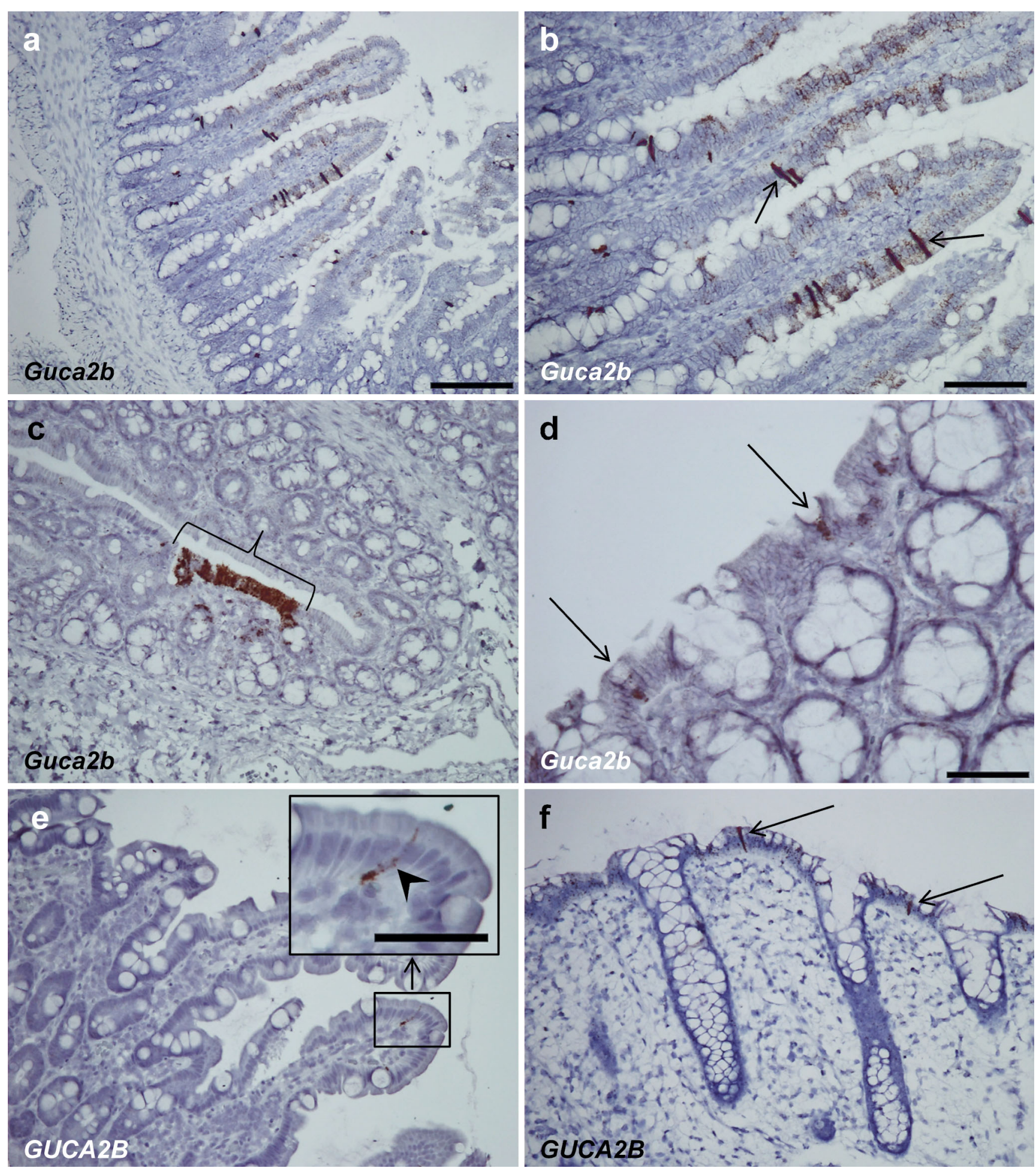

Fig. 2 Guca2b and GUCA2B expression in rat and human duodenum and colon. a, b Guca2b expression in rat duodenal mucosa. Expression of Guca $2 b$ is strong in scattered epithelial cells. Some of these cells (b) display a central swelling and narrow apical and basal parts (arrows). Additionally, scattered small black dots can be seen in other epithelial cells, indicating that expression is not entirely specific to a distinct cell type. Guca $2 b$ does not seem to be expressed in crypt epithelium. c Focal

expression of Guca2b in rat colonic epithelium (bracket). d Two cells (solid arrows), probably goblet cells, expressing Guca2b in rat colon. e Solitary $G U C A 2 B$-expressing epithelial cell of a human duodenal villus (insert, arrowhead). $\mathbf{f}$ Two epithelial cells expressing GUCA2B in human colon (solid arrows). Some small black dots can also be spotted in other cells of the superficial colonic epithelium. Bars $50 \mu \mathrm{m}$ (d, insert in e), $100 \mu \mathrm{m}(\mathbf{b}, \mathbf{c}, \mathbf{e}, \mathbf{f}), 200 \mu \mathrm{m}$ (a) 
Guca2b (UGN) expression in rat duodenal mucosa was widespread with mRNA being present to some degree in most cells of the duodenal villi. However, some epithelial cells had intense expression and clearly stood out (Fig. 2a, b). Guca2b expression was seldom present in the rat colon and seemed to be localized to clustered colonocytes and occasionally goblet cells (Fig. 2c, d). Contrary to the expression of Guca $2 b$ in rat duodenum, $G U C A 2 B$ expression in human duodenum was considerably less pronounced and was limited to scattered epithelial cells within the duodenal villi (Fig. 2e). In the human colon, GUCA2B was mainly strongly expressed in solitary superficial epithelial cells but scattered positivity for $G U C A 2 B$ could also be seen in other superficial epithelial cells (Fig. 2f).

Use of duplex ISH in rat duodenum gave no convincing evidence for the co-expression of Guca $2 b$ and Chga $(\mathrm{CgA})$ in strongly Guca $2 b$-expressing cells (Fig. 3a-d). In human duodenum, neither $G U C A 2 A$ - nor $G U C A 2 B$-positive cells coexpressed $C H G A(\mathrm{CgA})$ (Fig. 3e, f). Serial sections of rat duodenum with conventional single-plex ISH for $G u c a 2 b$ and Chga also showed no overlap between strongly Guca2b-expressing cells and Chga. However, some of the Chga-expressing cells might also have expressed some Guca $2 b$ given the weak and widespread expression of Guca2b (Fig. S2a, b). This is also subtly indicated by duplex ISH in some Chga-expressing cells (Fig. 3c, d, see also Fig. S2c, d). Serial sections of the human colon also gave no indication of the co-expression of $C H G A$ in strongly GUCA2B-expressing cells (Fig. S2e, f).

Again, we found no overlap of distinctly Guca $2 b /$ $G U C A 2 B$-expressing cells and selected tuft cell markers (Dclk1/DCLK1, Sox9/SOX9, Gnat3/GNAT3, or Trpm5/ TRPM5; Fig. S3a-h) by using conventional single-plex ISH and serial sections (micrographs from human duodenum are not shown). As we questioned the sensitivity of the Dclk1/ $D C L K 1$ probes, we also ran serial sections for Guca2b/ GUCA2B single-plex ISH and Dclk1 IHC. Dclk1 IHC might have shown slightly better sensitivity for Dclk1 than ISH, especially in rat duodenum but again, we saw no convincing overlap between Guca2b/GUCA2B and Dclk1 (Fig. S4a-h).

As Chga/CHGA might not be expressed in all subtypes of EE cells (Cetin et al. 1989), we also examined rat and human duodenal mucosa for the expression of insulinoma-associated 1 (Insm1/INSM1), which has been shown to be expressed in EE cells and required for their differentiation (Gierl et al. 2006). In human duodenum, INSM1 was scarcely expressed compared with $C H G A$ (Fig. S5a-d). In rat duodenum, we found a slightly higher expression of Insml (Fig. S6a-d); however, the expression of Insm 1 was considerably less than for both Chga and Guca2b (Fig. S6e, f). Additionally, Insm 1 was mostly expressed in crypt cells compared with Guca2b, which was predominantly expressed in duodenal villi (Fig. S6a-c, f).
The IHC results for GN on human duodenal and colonic sections (Fig. S7a, b) were comparable with the ISH results (Fig. 1c, f). Immunoreactivity for GN was seen in duodenal crypts consistent with localization in Paneth cells, in a few epithelial cells of the duodenal villi and in the entire superficial epithelium of the human colon. Unfortunately, because of a lack of appropriate antibodies for human and rat, we were not able to perform IHC for GN in rat or for UGN in human and rat.

For human GUCA2A mRNA (ISH) and GN peptide (IHC), abundance was much higher in duodenal crypt cells than in duodenal villi (Table 2). In each duodenal section, one can expect $>20$ positive crypt cells for every positive villous cell. Approximately half of the cells in human duodenal crypts express or synthesize $G U C A 2 A / \mathrm{GN}$, whereas one would expect to find from none to two $G U C A 2 A / \mathrm{GN}$-positive cells in every duodenal villus.

In human duodenum, the average numbers of $G U C A 2 B$ and $C H G A$-expressing cells were 4.1 and 86.8 per visual field $(200 \times)$, respectively, whereas the average numbers of Guca 2 b- and Chga-expressing cells in rat duodenum were 85.6 and 173.0 per visual field $(200 \times)$, respectively (Table 3 ).

\section{Discussion}

The current study focuses on the cellular localization of GUCA2A/Guca $2 a(\mathrm{GN})$ and GUCA2B/Guca2b (UGN) mRNAs in the duodenum and colon of both human and rat. Species differences are obvious in the duodenum. In the rat, Guca $2 a$ is distinctly expressed in goblet cells, as confirmed by serial sectioning and duplex ISH with Muc2. Paneth cells in rat do not express Guca2a; there is an absence of Guca2a expression deep in duodenal crypts and of co-expression with Defa6 in duplex ISH. In human duodenal mucosa, however, GUCA2A is expressed in Paneth cells, with overlapping expression with DEFA6. Moreover, the expression of GUCA2A in the human duodenal villi is limited to scattered epithelial cells and is not localized to goblet cells, consistent with previous findings in human gastrointestinal tissue (Date et al. 1996). Overall, the species differences are in concordance with previously observed differences (Cohen et al. 1995, 1998; Date et al. 1996; de Sauvage et al. 1992; Li and Goy 1993; Li et al. 1995).

The expression of GUCA2A/Guca2a in rat and human colon, however, is similar. We found colonic GUCA2A/Guca2a expression in human and rat to be present in the entire surface epithelium and, consequently, this should be present in both goblet cells and colonocytes, similar to previous findings (Date et al. 1996; Lewis et al. 1993). In rat, the release of $\mathrm{GN}$ into the colonic lumen has previously been determined to be 40 -fold higher than in portal effluents after stimulation (Moro et al. 2000). GN acts in a luminocrine (both paracrine 

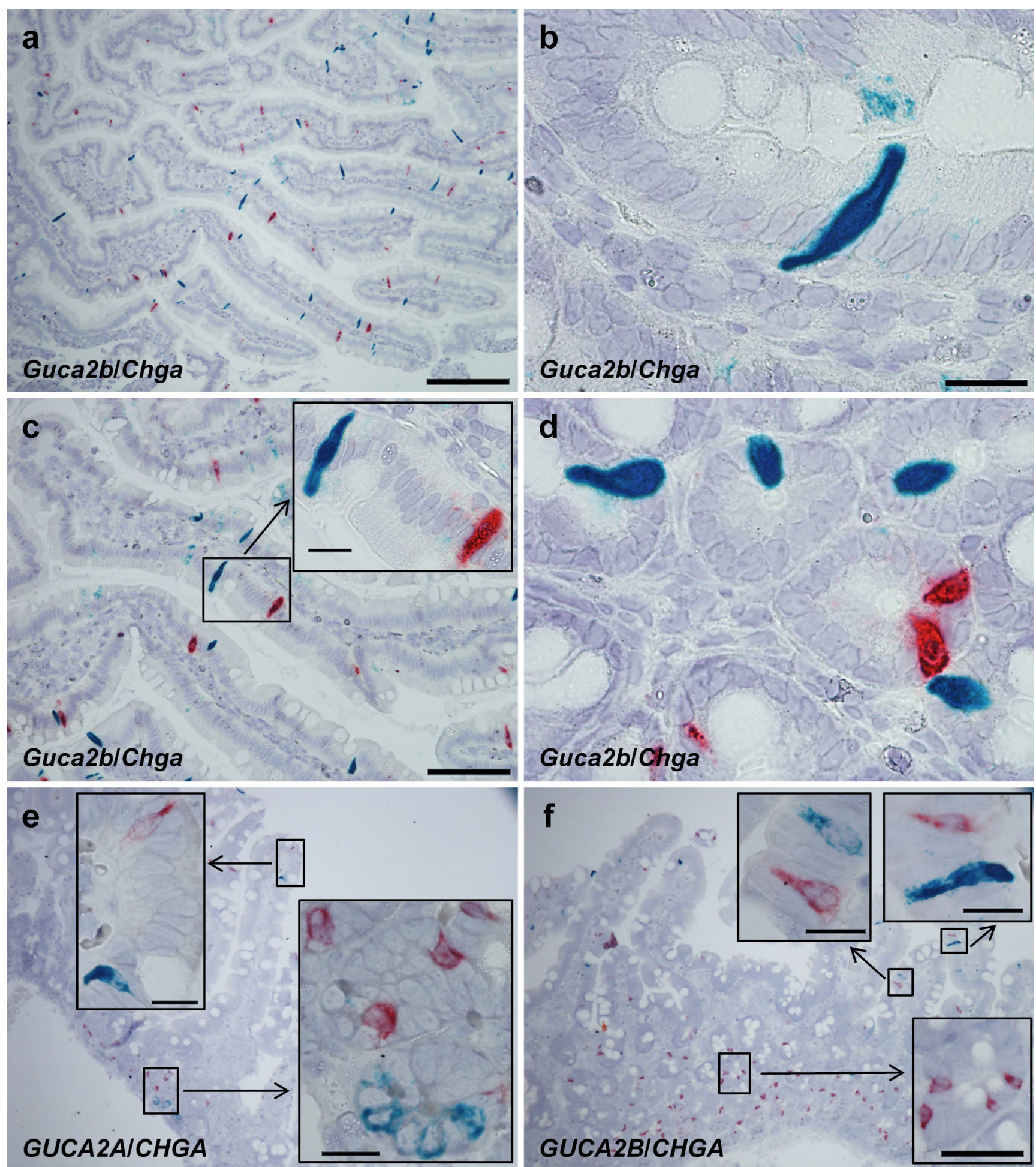

Fig. 3 Duplex ISH of Guca2b/Chga, GUCA2B/CHGA, and GUCA2A/ $C H G A$ in rat and human duodenum. a Duplex ISH of Guca2b (blue) and Chga (red) showing no definitive signs of co-expression of Chga and Guca $2 b$ in rat duodenum. b, c Morphology of Guca2b-expressing (blue) epithelial cells in rat duodenal villi. The cells have a central thickening and basal and apical narrowing. Whereas b displays no Chga-expressing cells (red), the Guca2b-expressing cell (blue) in $\mathbf{c}$ is accompanied by an adjacent Chga-expressing cell (red). The Chga-expressing cell in c

contains some scattered blue dots indicating some Guca2b expression. d Guca $2 b$ (blue) and Chga (red) expression in crypt cells, without overlap in the blue Guca2b-expressing cells. However, in the red Chga-expressing cells, blue dots indicate co-expression of Guca2b. e, f In human duodenum, co-expression cannot be seen for GUCA2A (blue) and CHGA (red) or for GUCA2B (blue) and CHGA (red); see inserts. Bars $20 \mu \mathrm{m}$ (b, d, inserts in c, e, upper inserts in f), $50 \mu \mathrm{m}$ (lower insert in $\mathbf{f}$ ), $100 \mu \mathrm{m}(\mathbf{c}), 200 \mu \mathrm{m}(\mathbf{a}, \mathbf{e}, \mathbf{f})$ 
Table 2 Number of GN-positive (IHC immunohistochemistry) and GUCA2A-positive (ISH in situ hybridization) cells of human duodenum (crypts and villi)

\begin{tabular}{lllll}
\hline GUCA2A/GN (entire biopsy) & Positive crypt cells & Counted crypts & Positive villous cells & Counted villi \\
\hline Section 1 (IHC) & 237 & 99 & 12 & 30 \\
Section 2 (IHC) & $>250$ & $>100$ & 0 & 43 \\
Section 3 (ISH) & 56 & 26 & 13 & 13 \\
Section 4 (ISH) & 116 & 61 & 12 & 7 \\
\hline
\end{tabular}

and autocrine) manner via activation of the $\mathrm{GC}-\mathrm{C}$ receptor. The GC-C receptor is expressed throughout the intestinal epithelium of both human and rat (Krause et al. 1994; Qian et al. 2000). In human small intestine, the receptor density decreases longitudinally in the small intestine, whereas within the vertical axis of villi and crypts of the small intestine, the greatest density is observed in the basal half of the villi and in the neck region of intestinal glands (Krause et al. 1994). In the colon, the receptor is found both in superficial epithelial cells and in colonic glands (Krause et al. 1994).

In human duodenum, GUCA2A is expressed in Paneth cells, which secrete anti-microbial peptides and additionally, Guca2a/ GUCA2A is expressed in mucus-secreting goblet cells in rat duodenum and in rat and human colon, a critical characteristic for epithelial defense (Van der Sluis et al. 2006). Some natriuretic peptides have antibacterial properties; however, we are only aware of one study in which GN and UGN have been tested and found to have lower antimicrobial activity (Krause et al. 2001).

We found no overlap of GUCA2A and CHGA (CgA) in human duodenal mucosa. Previous studies on mucosal sections identified GN in EE (EC and D) cells (Cetin et al. 1994; Hill et al. 1995; Ieda et al. 1998). Similarly, increased Guca2a expression has been seen in fluorescence-activated-sorted EC cells of Mastomys compared with the intestinal mucosa (Kidd et al. 2006) and serum GN is elevated in patients with carcinoid tumors (Kuhn et al. 1995). Others, on the other hand, found no colocalization of GN and $\mathrm{CgA}$, serotonin, glucagon, pancreatic polypeptide, vasoactive intestinal polypeptide, or somatostatin (Date et al. 1996). Previously, most epithelial cell lineages have been postulated to express GN mRNA (Cohen et al. 1998). Our

Table 3 Numbers of distinctly Guca2b/GUCA2B-expressing cells compared with $\mathrm{Chga} / \mathrm{CHGA}$-expressing cells in rat and human duodenum (STD standard deviation)

\begin{tabular}{lllllll}
\hline Statistic & Guca2b $^{\mathrm{a}}$ & Chga $^{\mathrm{a}}$ & $P^{\dagger}$ & GUCA2B $^{\mathrm{b}}$ & CHGA $^{\mathrm{c}}$ & $P^{\ddagger}$ \\
\hline Average & 85.6 & 173.0 & 0.001 & 4.1 & 86.8 & 0.002 \\
STD & 22.1 & 35.6 & & 5.1 & 15.0 & \\
\hline
\end{tabular}

Magnification 200×

$\dagger$ Student $t$-test equal variance

+ Student $t$-test unequal variance.

${ }^{a}$ Five visual fields from two sections were examined

${ }^{\mathrm{b}}$ Eight visual fields from two sections were examined

${ }^{\mathrm{c}}$ Four visual fields from two sections were examined findings in the colon of both human and rat indicate that GN is not entirely specific to a particular cell type, as the entire colonic epithelium seems to express GUCA2A/Guca2a. In any case, the current findings are in harmony with most previous IHC or ISH studies regarding GN and RNA Scope ISH technology is also extremely robust with high specificity and sensitivity, given a successful probe (Sordal et al. 2013).

Guca $2 b$ was strongly expressed in distinct cells of the rat duodenum and was additionally widespread, although weak expression was seen in other epithelial cells of the duodenal villi. Thus, the possibility that some EC cells also express Guca $2 b$ is high. Indeed, we demonstrated this with duplex ISH in rat duodenum in which subtle Guca $2 b$ expression could be detected in Chga-expressing cells. This is partly consistent with previous findings in rat jejunum in which most serotonin-positive cells are UGN-positive and vice versa, although a subset of positive cells is only positive for each peptide (Perkins et al. 1997). In the same study, no colocalization of cholecystokinin (CCK)-synthesizing I-cells and UGN was seen. In our study, the epithelial cells that displayed intense $G u c a 2 b$ expression clearly stood out from the rest of the epithelial cell population. These cells did not display Chga expression and are therefore probably not EC cells (Portela-Gomes et al. 1997). Thus, these predominantly Guca2b-expressing cells might be a different and possibly not yet characterized, cell type. In rat colon, Guca2b expression is patchy in what appears to be colonocytes. Guca $2 b$ is also expressed in some rat colonic cells with a goblet cell appearance, further indicating that Guca2b expression is not entirely cell-specific and might be induced in multiple cell types.

$G U C A 2 B$ expression seems to be more specific in humans. In the duodenum, expression is limited to a small number of solitary epithelial cells of the duodenal villi, whereas colonic $G U C A 2 B$ expression is mainly localized to distinct superficial cells. These cells do not seem to express $C H G A$; however, this was only determined by the interpretation of serial sections. Whether these cells also represent a specific cell type as suggested for rat duodenum remains to be clarified. Two previous studies have indicated that human UGN is synthesized in EE cells of the colon (Hess et al. 1995) and in D cells in the stomach (Mägert et al. 1998). These investigations and our study are, to the best of our knowledge, the only ones to show cell-specific cellular localization of $\mathrm{UGN} / G U C A 2 B$; we are not aware of other studies showing cell-specific localization of human $\mathrm{UGN} / G U C A 2 B$ in the duodenum or small intestine. 
The loss of GC-C signaling has been shown to disrupt satiety and food intake decreases after UGN injection in mice (Valentino et al. 2011). Thus, GUCA2B/Guca2b-expressing cells in the small intestine probably have sensory properties and might be of importance in the pathogenesis of obesity. Additionally, circulating GN and UGN regulate natriuresis (Mueller and Dieplinger 2012). From the morphology of many of the Guca2b cells presented in this paper, we speculate that these cells might be tuft cells. Tuft cells, also referred to as brush or caveolated cells (Kokrashvili et al. 2009), are scattered epithelial cells, having been recognized as a distinct cell type in rat tracheal epithelium in 1956 (Rhodin and Dalhamn 1956). Morphologically, they are characterized by narrow apical and basal parts and a swelling of the nuclear portion, with apical microvilli (Sato 2007). Proposed functions are absorptive, secretory and chemoreceptive (Sato 2007). Transient receptor potential cation channel (Trpm5)expressing tuft cells in mice have been proposed as a cellular source for UGN (Kokrashvili et al. 2009). These cells do not express $\mathrm{CgA}$ or $\mathrm{CgB}$ or any associated peptide or amine (Kokrashvili et al. 2009). Several tuft cell markers have been proposed, including calmodulin-dependent protein kinaselike-1 (Dclk1), Trpm5, $\alpha$-gustducin (Gnat3) and sexdetermining region Y-box (Sox9; Gerbe et al. 2012). Dlck1 is categorized as a structural marker, whereas Gnat3 and Trpm5 are termed taste-cell-related markers (Gerbe et al. 2012). Sox 9 is not entirely tuft-cell-specific but is also expressed in Paneth cells and is essential for their differentiation (Gerbe et al. 2011). In serial human and rat duodenal sections stained by using the above-mentioned tuft cell markers, we have, however, been unable to determine coexpression with $G U C A 2 B / G u c a 2 b$-expressing cells. The expression of two of these proposed tuft cell markers, namely DCLK1/Dclk1 and GNAT3/Gnat3, is scarce (especially in human intestine) and expression levels are significantly lower than those for GUCA2B/Guca2b. The Dclk1 IHC signal seems to show better sensitivity for Dclk1 than in ISH, suggesting that the probes for $D C L K 1 / D c l k 1$ are not optimal or that expression is temporal and varying. SOX9/Sox 9 is also rarely expressed in duodenal villi but pronounced expression has been noted deep in the crypts, consistent with its expression in Paneth cells. TRPM5/Trpm5 is expressed both in solitary epithelial cells of the duodenal villi and at the base of the crypts. Strongly $G U C A 2 B / G u c a 2 b$-expressing cells thus probably represent a specific cell type but in the absence of a reliable and consistent tuft cell marker, the assignment of UGN to the tuft cell might be difficult.

One limitation of this study is the inability to perform IHC for rat GN and both human and rat UGN because of a lack of good, commercially available antibodies. Another limitation is that $\mathrm{CgA}$ is questioned as a universal marker for EE cells (Cetin et al. 1989). The latter study shows that D-, CCK- and motilin (Mo)-positive cells display little $\mathrm{CgA}$ immunoreactivity and that significant inter- and intra-species variation is present. However, other studies have also demonstrated some CgA immunoreactivity in D cell (Portela-Gomes et al. 1997). Other EE cells and the EC cell, in particular, stain for CgA (Portela-Gomes et al. 1997). IHC might also have limitations in this setting, as different antisera raised against different $\mathrm{CgA}$ epitopes display variable immunoreactivity against $\mathrm{CgA}$ and the $\mathrm{D}$ cell might also be positive when examined with the appropriate antibody (Norlén et al. 2001). Thus, ISH might be advantageous for the detection of CHGA/Chga expression in this setting, as the mRNA would not be exposed to the posttranslational modifications or degradation of the $\mathrm{CgA}$ protein. We also examined the expression of another proposed marker for EE cells, namely INSM1/ Insm1 (Gierl et al. 2006) but found that expression is very weak compared with that for CHGA/Chga. In view of the difficulties in performing IHC, the ISH technology used in this study is an excellent substitute and we also believe that it is advantageous given its high sensitivity and specificity (Sordal et al. 2013).

In conclusion, by use of a highly sensitive and specific ISH method, we found that a similar pattern of cellular GUCA2A/ Guca2a mRNA expression is present in human and rat colon (goblet cells and colonocytes). However, distinct interspecies differences are apparent in duodenal GUCA2A/Guca2a mRNA and in duodenal and colonic GUCA2B/Guca2b mRNA expression. In the human duodenum, GUCA2A is expressed in Paneth cells and in a few solitary villous epithelial cells, whereas in the rat duodenum, Guca2a is abundantly expressed in goblet cells. We found no evidence for the coexpression of GUCA2A and GUCA2B with $C H G A$ in human intestine. Strongly Guca $2 b$-expressing cells of rat duodenum also do not co-express Chga. Thus, EC cells are unlikely to be the main source for GN or UGN in humans and for UGN in rat. Some EE cells, at least in rat, are probably a minor source for UGN. This is also consistent with previous findings. However, the tuft cell, in particular, should be further examined, as UGN might be a major secretory product thereof. Furthermore, this is, to the best of our knowledge, the first study to show the expression of GUCA2B at the cellular level in human duodenum. Additional studies are needed to determine more precisely the cellular sources of, especially, UGN in humans and other species and of GN in human duodenum. Quantification of both GUCA2A- and GUCA2B-expressing cells should be conducted in the various small intestinal segments of humans.

Open Access This article is distributed under the terms of the Creative Commons Attribution 4.0 International License (http:// creativecommons.org/licenses/by/4.0/), which permits unrestricted use, distribution, and reproduction in any medium, provided you give appropriate credit to the original author(s) and the source, provide a link to the Creative Commons license, and indicate if changes were made. 


\section{References}

Beltowski J (2001) Guanylin and related peptides. J Physiol Pharmacol $52: 351-375$

Brenna O, Bruland T, Furnes MW, Granlund A, Drozdov I, Emgard J, Bronstad G, Kidd M, Sandvik AK, Gustafsson BI (2015) The guanylate cyclase-C signaling pathway is down-regulated in inflammatory bowel disease. Scand J Gastroenterol 50:1241-1252

Castro J, Harrington AM, Hughes PA, Martin CM, Ge P, Shea CM, Jin H, Jacobson S, Hannig G, Mann E, Cohen MB, MacDougall JE, Lavins BJ, Kurtz CB, Silos-Santiago I, Johnston JM, Currie MG, Blackshaw LA, Brierley SM (2013) Linaclotide inhibits colonic nociceptors and relieves abdominal pain via guanylate cyclase-C and extracellular cyclic guanosine $3^{\prime}, 5^{\prime}$-monophosphate. Gastroenterology 145:1334-1346

Cetin Y, Müller-Köppel L, Aunis D, Bader MF, Grube D (1989) Chromogranin A (CgA) in the gastro-entero-pancreatic (GEP) endocrine system. Histochemistry 92:265-275

Cetin Y, Kuhn M, Kulaksiz H, Adermann K, Bargsten G, Grube D, Forssmann WG (1994) Enterochromaffin cells of the digestive system: cellular source of guanylin, a guanylate cyclase-activating peptide. Proc Natl Acad Sci U S A 91:2935-2939

Chey WD, Lembo AJ, Lavins BJ, Shiff SJ, Kurtz CB, Currie MG, MacDougall JE, Jia XD, Shao JZ, Fitch DA, Baird MJ, Schneier HA, Johnston JM (2012) Linaclotide for irritable bowel syndrome with constipation: a 26-week, randomized, double-blind, placebocontrolled trial to evaluate efficacy and safety. Am J Gastroenterol 107:1702-1712

Cohen MB, Witte DP, Hawkins JA, Currie MG (1995) Immunohistochemical localization of guanylin in the rat small intestine and colon. Biochem Biophys Res Commun 209:803-808

Cohen MB, Hawkins JA, Witte DP (1998) Guanylin mRNA expression in human intestine and colorectal adenocarcinoma. Lab Invest 78: $101-108$

Cui L, Blanchard RK, Coy LM, Cousins RJ (2000) Prouroguanylin overproduction and localization in the intestine of zinc-deficient rats. $\mathrm{J}$ Nutr 130:2726-2732

Currie MG, Fok KF, Kato J, Moore RJ, Hamra FK, Duffin KL, Smith CE (1992) Guanylin: an endogenous activator of intestinal guanylate cyclase. Proc Natl Acad Sci U S A 89:947-951

Date Y, Nakazato M, Yamaguchi H, Miyazato M, Matsukura S (1996) Tissue distribution and plasma concentration of human guanylin. Intern Med 35:171-175

Date Y, Nakazato M, Yamaguchi H, Kangawa K, Kinoshita Y, Chiba T, Ueta Y, Yamashita H, Matsukura S (1999) Enterochromaffin-like cells, a cellular source of uroguanylin in rat stomach. Endocrinology 140:2398-2404

de Sauvage FJ, Keshav S, Kuang WJ, Gillett N, Henzel W, Goeddel DV (1992) Precursor structure, expression, and tissue distribution of human guanylin. Proc Natl Acad Sci U S A 89:9089-9093

Field M (2003) Intestinal ion transport and the pathophysiology of diarrhea. J Clin Invest 111:931-943

Field M, Graf LH, Laird WJ, Smith PL (1978) Heat-stable enterotoxin of Escherichia coli: in vitro effects on guanylate cyclase activity, cyclic GMP concentration, and ion transport in small intestine. Proc Natl Acad Sci U S A 75:2800-2804

Fiskerstrand T, Arshad N, Haukanes BI, Tronstad RR, Pham KD, Johansson S, Havik B, Tonder SL, Levy SE, Brackman D, Boman H, Biswas KH, Apold J, Hovdenak N, Visweswariah SS, Knappskog PM (2012) Familial diarrhea syndrome caused by an activating GUCY2C mutation. N Engl J Med 366:1586-1595

Gerbe F, van Es JH, Makrini L, Brulin B, Mellitzer G, Robine S, Romagnolo B, Shroyer NF, Bourgaux JF, Pignodel C, Clevers H, Jay P (2011) Distinct ATOH1 and Neurog3 requirements define tuft cells as a new secretory cell type in the intestinal epithelium. J Cell Biol 192:767-780

Gerbe F, Legraverend C, Jay P (2012) The intestinal epithelium tuft cells: specification and function. Cell Mol Life Sci 69:2907-2917

Gierl MS, Karoulias N, Wende H, Strehle M, Birchmeier C (2006) The zinc-finger factor Insm1 (IA-1) is essential for the development of pancreatic $\beta$ cells and intestinal endocrine cells. Genes Dev 20: $2465-2478$

Hamra FK, Forte LR, Eber SL, Pidhorodeckyj NV, Krause WJ, Freeman RH, Chin DT, Tompkins JA, Fok KF, Smith CE et al (1993) Uroguanylin: structure and activity of a second endogenous peptide that stimulates intestinal guanylate cyclase. Proc Natl Acad Sci U S A 90:10464-10468

Han X, Mann E, Gilbert S, Guan Y, Steinbrecher KA, Montrose MH, Cohen MB (2011) Loss of guanylyl cyclase C (GCC) signaling leads to dysfunctional intestinal barrier. PLoS One 6:e16139

Hess R, Kuhn M, Schulz-Knappe P, Raida M, Fuchs M, Klodt J, Adermann K, Kaever V, Cetin Y, Forssmann W-G (1995) GCAPII: isolation and characterization of the circulating form of human uroguanylin. FEBS Lett 374:34-38

Hill O, Kuhn M, Zucht HD, Cetin Y, Kulaksiz H, Adermann K, Klock G, Rechkemmer G, Forssmann WG, Magert HJ (1995) Analysis of the human guanylin gene and the processing and cellular localization of the peptide. Proc Natl Acad Sci U S A 92:2046-2050

Hughes JM, Murad F, Chang B, Guerrant RL (1978) Role of cyclic GMP in the action of heat-stable enterotoxin of Escherichia coli. Nature 271:755-756

Ieda H, Naruse S, Furuya S, Ozaki T, Ando E, Nokihara K, Hori S, Kitagawa M, Hayakawa T (1998) Coexistence of proguanylin (1$15)$ and somatostatin in the gastrointestinal tract. J Gastroenterol Hepatol 13:1225-1233

Kidd M, Modlin IM, Eick GN, Champaneria MC (2006) Isolation, functional characterization, and transcriptome of Mastomys ileal enterochromaffin cells. Am J Physiol Gastrointest Liver Physiol 291: G778-G791

Kokrashvili Z, Rodriguez D, Yevshayeva V, Zhou H, Margolskee RF, Mosinger B (2009) Release of endogenous opioids from duodenal enteroendocrine cells requires Trpm5. Gastroenterology 137:598-606

Krause WJ, Cullingford GL, Freeman RH, Eber SL, Richardson KC, Fok KF, Currie MG, Forte LR (1994) Distribution of heat-stable enterotoxin/guanylin receptors in the intestinal tract of man and other mammals. J Anat 184:407-417

Krause A, Liepke C, Meyer M, Adermann K, Forssmann WG, Maronde E (2001) Human natriuretic peptides exhibit antimicrobial activity. Eur J Med Res 6:215-218

Kuhn M, Kulaksiz H, Cetin Y, Frank M, Nold R, Arnold R, Boker K, Bischoff SC, Manns MP, Forssmann WG (1995) Circulating and tissue guanylin immunoreactivity in intestinal secretory diarrhoea. Eur J Clin Invest 25:899-905

Lewis LG, Witte DP, Laney DW, Currie MG, Cohen MB (1993) Guanylin mRNA is expressed in villous enterocytes of the rat small intestine and superficial epithelia of the rat colon. Biochem Biophys Res Commun 196:553-560

Li Z, Goy MF (1993) Peptide-regulated guanylate cyclase pathways in rat colon: in situ localization of GCA, GCC, and guanylin mRNA. Am J Physiol 265:G394-G402

Li Z, Taylor-Blake B, Light AR, Goy MF (1995) Guanylin, an endogenous ligand for C-type guanylate cyclase, is produced by goblet cells in the rat intestine. Gastroenterology 109:1863-1875

Lin JE, Li P, Snook AE, Schulz S, Dasgupta A, Hyslop TM, Gibbons AV, Marszlowicz G, Pitari GM, Waldman SA (2010) The hormone receptor GUCY2C suppresses intestinal tumor formation by inhibiting AKT signaling. Gastroenterology 138:241-254

Mägert H-J, Reinecke M, David I, Hans-Rudolf R, Adermann K, Zucht H-D, Hill O, Rüdiger H, Forssmann W-G (1998) Uroguanylin: gene 
structure, expression, processing as a peptide hormone, and costorage with somatostatin in gastrointestinal D-cells. Regul Pept $73: 165-176$

Moro F, Levenez F, Nemoz-Gaillard E, Pellissier S, Plaisancie P, Cuber JC (2000) Release of guanylin immunoreactivity from the isolated vascularly perfused rat colon. Endocrinology 141:2594-2599

Mueller T, Dieplinger B (2012) The guanylin peptide family and the proposed gastrointestinal-renal natriuretic signaling axis. Kidney Int 82:1253-1255

Nakazato M, Yamaguchi H, Date Y, Miyazato M, Kangawa K, Goy MF, Chino N, Matsukura S (1998) Tissue distribution, cellular source, and structural analysis of rat immunoreactive uroguanylin. Endocrinology 139:5247-5254

Norlén P, Curry WJ, Björkqvist M, Maule A, Cunningham RT, Hogg RB, Harriott P, Johnston CF, Hutton JC, Håkanson R (2001) Cellspecific processing of chromogranin $\mathrm{A}$ in endocrine cells of the rat stomach. J Histochem Cytochem 49:9-18

Perkins A, Goy MF, Li Z (1997) Uroguanylin is expressed by enterochromaffin cells in the rat gastrointestinal tract. Gastroenterology 113: $1007-1014$

Portela-Gomes GM, Stridsberg M, Johansson H, Grimelius L (1997) Complex co-localization of chromogranins and neurohormones in the human gastrointestinal tract. J Histochem Cytochem 45:815-822

Qian X, Prabhakar S, Nandi A, Visweswariah SS, Goy MF (2000) Expression of GC-C, a receptor-guanylate cyclase, and its endogenous ligands uroguanylin and guanylin along the rostrocaudal axis of the intestine. Endocrinology 141:3210-3224
Rhodin J, Dalhamn T (1956) Electron microscopy of the tracheal ciliated mucosa in rat. Z Zellforsch Mikrosk Anat 44:345-412

Sato A (2007) Tuft cells. Anat Sci Int 82:187-199

Schulz S, Green CK, Yuen PS, Garbers DL (1990) Guanylyl cyclase is a heat-stable enterotoxin receptor. Cell 63:941-948

Sindic A, Schlatter E (2006) Cellular effects of guanylin and uroguanylin. J Am Soc Nephrol 17:607-616

Sordal O, Qvigstad G, Nordrum IS, Gustafsson B, Waldum HL (2013) In situ hybridization in human and rodent tissue by the use of a new and simplified method. Appl Immunohistochem Mol Morphol 21: 185-189

Valentino MA, Lin JE, Snook AE, Li P, Kim GW, Marszalowicz G, Magee MS, Hyslop T, Schulz S, Waldman SA (2011) A uroguanylin-GUCY2C endocrine axis regulates feeding in mice. $\mathrm{J}$ Clin Invest 121:3578-3588

Van der Sluis M, De Koning BA, De Bruijn AC, Velcich A, Meijerink JP, Van Goudoever JB, Buller HA, Dekker J, Van Seuningen I, Renes IB, Einerhand AW (2006) Muc2-deficient mice spontaneously develop colitis, indicating that MUC2 is critical for colonic protection. Gastroenterology 131:117-129

Whitaker TL, Witte DP, Scott MC, Cohen MB (1997) Uroguanylin and guanylin: distinct but overlapping patterns of messenger RNA expression in mouse intestine. Gastroenterology 113:1000-1006

Wilson C, Lin JE, Li P, Snook AE, Gong J, Sato T, Liu C, Girondo MA, Rui H, Hyslop T, Waldman SA (2014) The paracrine hormone for the GUCY2C tumor suppressor, guanylin, is universally lost in colorectal cancer. Cancer Epidemiol Biomark Prev 23:2328-2337 